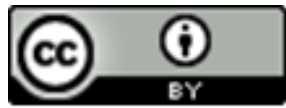

\title{
ENSINAR NO QUILOMBO, ENSINAR O QUILOMBO: ESCOLARIZAÇÃO E IDENTIDADE RACIAL DOCENTE ${ }^{1}$
}

\author{
Alan Augusto Moraes Ribeiro ${ }^{2}$ \\ Universidade Federal do Oeste do Pará, Instituto de Ciências da Educação, Programa \\ de Educação, Departamento de Pedagogia, Santarém, Pará, Brasil
}

\begin{abstract}
Resumo: A crescente discussão acadêmica sobre Educação Escolar Quilombola tem envolvido mais abordagens conceituais acerca do que ela deve ser do que a análise a partir das/os professoras/es quilombolas e não-quilombolas fazem em suas práticas docentes. A partir das práticas docentes destas/es professoras/es uma escola localizada em um território quilombola, apresento neste artigo uma análise acerca de três aspectos diretamente associados: a) reflexões sobre as próprias práticas pedagógicas dentro da escola realizadas pelas/es professoras/es, b) relatos individuais sobre como ocorre o processo de escolarização no cotidiano da escola, concebida de maneira variável como "escola quilombola" e como "escola no território quilombola" e c) narrativas e relatos usados para definir pedagogicamente o que cada docente concebe em sua própria prática profissional como educação escolar quilombola. Três contraposiões aparecem entre os relatos de professoras/es quilombolas e as professoras/es não-quilombolas: I) maneiras pelas quais o experiência comunitária é trazida para a prática docente, mediando quem tem mais ou menos conhecimento sobre a cultura do quilombo; II) caminhos pelos quais uma certa pedagogia escolar quilombola pode ser elaborada conceitualmente, envolvendo valores e finalidades distintas; III) lugar das discussões sobre racismo, identidade étnico-racial e auto-estima racial, apresentados como aspectos intimamente associados, mas percebidos sob difentes ordens de relevância pedagógica e política.
\end{abstract}

Palavras-Chave: quilombo; escolarização; identidade étnico-racial

\section{TEACHING IN THE QUILOMBO, TEACHING THE QUILOMBO: SCHOOLING AND TEACHER RACIAL IDENTITY}

\footnotetext{
${ }^{1}$ Uma versão resumida deste artigo foi publicada na Série Cadernos Flacso Brasil. Ver: SOUZA, Greyssy Kelly Araujo (org.). Práticas Comunitárias Educacionais brasileiras e suas territorialidades [livro eletrônico] Brasília: Faculdade Latino Americana de Ciências Sociais, n. 19, 2021.

${ }^{2}$ Professor do Instituto de Ciências da Educação, da Universidade Federal do Oeste do Pará (ICEDUFOPA) Pesquisa raça, classe, gênero/masculinidades, sociabilidade juvenil, educação escolar quilombola, desempenho escolar, relações étnico-raciais para a educação escolar. Docente do Programa de Pós-graduação em Educação (ICED-UFOPA). Líder do Grupo de Estudos e Pesquisas Raça, Educação e Etnicidades na Amazônia (GEREA). Integrante colaborador do Grupo de Estudos e Pesquisas EDGES (USP). E-mail: alan.ribeiro@ufopa.org.br ; ORCID: https://orcid.org/0000-0002-6899-2443
} 
Abstract: The growing academic discussion on Quilombola School Education has involved more conceptual approaches about what it should be than the analysis based on the Quilombola and non-Quilombola teachers do in their teaching practices. Based on the teaching practices of these teachers in a school located in a quilombola territory, I present in this article an analysis of three directly associated aspects: a) reflections on the pedagogical practices within the school carried out by the teachers, b) individual reports on how the schooling process takes place in the daily life of the school, conceived in a variable way as "quilombola school" and as "school in the quilombola territory" and c) narratives and reports used to pedagogically define what each teacher conceives in their own professional practice as quilombola school education. Three contrasts appear between the reports of Quilombola teachers and non-Quilombola teachers: I) ways in which the community experience is brought to teaching practice, mediating who has more or less knowledge about the Quilombo culture; II) ways in which a certain quilombola school pedagogy can be conceptually elaborated, involving different values and purposes; III) place of discussions on racism, ethnic-racial identity and racial self-esteem, presented as closely associated aspects, but perceived under different orders of pedagogical and political relevance.

Keywords: quilombo; schooling; ethnic-racial identity

\section{ENSEÑAR EN EL QUILOMBO, ENSEÑAR EN EL QUILOMBO: ESCOLARIDAD E IDENTIDAD RACIAL DEL MAESTRO}

Resumen: La creciente discusión académica sobre la Educación Escolar Quilombola ha involucrado enfoques más conceptuales sobre lo que debería ser que el análisis que hacen los docentes quilombolas y no quilombolas en sus prácticas docentes. A partir de las prácticas docentes de estos docentes en una escuela ubicada en un territorio quilombola, presento en este artículo un análisis de tres aspectos directamente asociados: a) reflexiones sobre las prácticas pedagógicas dentro de la escuela realizadas por los docentes, b) informes individuales sobre cómo se desarrolla el proceso de escolarización en la vida cotidiana de la escuela, concebida de manera variable como "escuela quilombola" y como "escuela en el territorio quilombola" yc) narrativas e informes utilizados para definir pedagógicamente lo que cada docente concibe en su propia práctica profesional como educación escolar quilombola. Aparecen tres contrastes entre los relatos de los maestros quilombolas y los no quilombolas: I) formas en que la experiencia comunitaria se lleva a la práctica docente, mediando quién tiene más o menos conocimiento sobre la cultura quilombola; II) formas en las que una determinada pedagogía escolar quilombola puede ser elaborada conceptualmente, involucrando diferentes valores y propósitos; III) lugar de las discusiones sobre el racismo, la identidad étnico-racial y la autoestima racial, presentados como aspectos estrechamente asociados, pero percibidos bajo diferentes órdenes de relevancia pedagógica y política.

Palabras-clave: quilombo; enseñanza; identidad étnico-racial

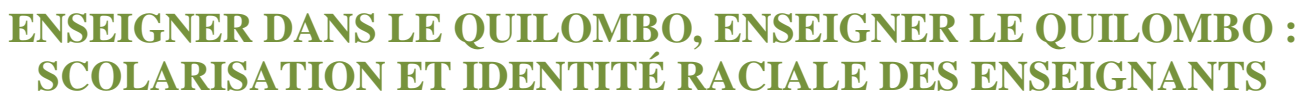


Résumé: La discussion académique croissante sur l'éducation scolaire Quilombola a impliqué plus d'approches conceptuelles sur ce qu'elle devrait être que l'analyse basée sur les enseignants Quilombola et non-Quilombola le font dans leurs pratiques d'enseignement. À partir des pratiques pédagogiques de ces enseignants dans une école située dans un territoire quilombola, je présente dans cet article une analyse de trois aspects directement associés : a) les réflexions sur les pratiques pédagogiques au sein de l'école menées par les enseignants, b) les rapports individuels sur la façon dont le processus de scolarisation se déroule dans la vie quotidienne de l'école, conçue de manière variable comme «école quilombola» et comme «école dans le territoire quilombola» et c) les récits et les rapports utilisés pour définir pédagogiquement ce que chaque enseignant conçoit dans son propre pratique professionnelle en tant qu'enseignement scolaire quilombola. Trois contrastes apparaissent entre les rapports des enseignants Quilombola et des enseignants non Quilombola : I) les manières dont l'expérience communautaire est apportée à la pratique de l'enseignement, en intervenant qui a plus ou moins de connaissances sur la culture Quilombo ; II) les manières dont une certaine pédagogie scolaire quilombola peut être élaborée de manière conceptuelle, impliquant différentes valeurs et objectifs; III) lieu de discussions sur le racisme, l'identité ethnico-raciale et l'estime de soi raciale, présentés comme des aspects étroitement associés, mais perçus sous différents ordres de pertinence pédagogique et politique.

Mots-clés: quilombo; scolarité; identité ethnico-raciale

\section{INTRODUÇÃO}

Quando observamos a já existente trajetória de pesquisas e debates acadêmicos desenvolvidos ao logo do século XX e início deste século XXI sobre história dos quilombos e quilombolas no Brasil, podemos concondar que, em princípio, duas vertentes interpretativas se sobressaem na abordagem sobre estas comunidades e indivíduos. A primeira consiste em um tipo de perspectiva culturalista, cujo elemento conceitual central reside na mobilização de uma concepção de minoria étnica territorial que apresenta historicamente as comunidades quilombolas como agentes coletivos de resistência cultural. Nesta primeira abordagem, proeminente entre estudos da primeira metade do séc. XX, “(...) escravos teriam fugido e se organizado para resistir culturalmente ao processo de opressão", de maneira que “(...) seria apenas nos quilombos que os africanos e seus descendentes poderiam preservar suas identidades étnicas". Por sua vez, a segunda vertente conceitual ou abordagem analítica, denominada por Flávio Gomes como materialista, apresenta os quilombos como grupos de resistência duradoura à escravidão e como oposição à opressão racial pós-escravidão através da ocupação histórica de um espaço geográfico em comuidades rurais (e em 
alguns casos, urbanas). Estas comunidades quilombolas foram capazes de construir algo como uma oposição ao racismo e uma territorialização anti-hegemônica (GOMES, 2015, p. 70-72). Ambas abordagens, postas assim, implicam em perspectivas analíticas que produzem um lugar de "marginalização" da existência dos quilombos, apresentando-os como “(...) mundos isolados, ora de resistência cultural, ora de luta contra o escravismo" (GOMES, 2015, p. 73)", cujas vivências sócio-culturais são lidas a partir deste lugar. Esta "vivência marginal" atribuída aos quilombos se relaciona com uma ideia corrente de ameaça às grandes fazendas e à tranquilidade das cidades e do mundo escravista, sobretudo durante o século XVIII e XIX.

Entretanto, sugerir que os quilombos possam ser pensados como lugares de vivência marginal implica em negligenciar alianças políticas, conexões sócio-culturais e negociações mercantis, sociais e culturais com a sociedade escravista externa aos territórios no período da escravidão e nos tempos da pós-escravidão (FREIRE; AMANTINO, 2013). Sair deste lugar de margem colocado sobre os quilombos nos leva a pensar historicamente os territórios e os indivíduos que neles vivem como sujeitos ativos de lugares de vivência autônoma dentro deste quadro de trocas e negociações que, desta maneira, permitia “(...) algum tipo de proteção contra os ataques externos [sendo] capazes de barganhar com os que viviam na localidade" (FREIRE; AMANTINO, 2013, p. 15; FUNES, 1995). Vale acrescentar que a existência de comunidades quilombolas nos séculos XVIII e XIX eram vistas como incentivo para outras fugas e insurreições, o que permitia a outros grupos sociais, incluindo pessoas brancas livres pobres, recorressem aos quilombos em busca de proteção e esconderijo. Talvez seja para um certo lugar polivalente dos quilombos que deveremos olhar ao discutimos a formação social das comunidades quilombolas a partir deste conjunto de estudos historiográficos e antropológicos.

Clóvis Moura (1993), por exemplo, com seu estudo sobre a formação, organização e articulação de uma prática da "quilombagem" no Brasil como resistência ao escravismo, que envolviam banditismo, sublevações locais, trabalho cooperativo e econômico e, chegou até mesmo a cogitar uma certa "articulação internacional da quilombagem", como resistência à opressão racial internacional do capitalismo. As pesquisas de Alfredo Wagner de Almeida (2002; 2012) sobre quilombolos no Maranhão, permitem discutir a adequação dos termos "terras de preto" e/ou "territórios 
quilombolas" quando olhamos tanto para o pertencimento racial não-negro de alguns moradores dos territórios, como também para as relações de trocas econômicas e culturais com outras comunidades próximas, incluindo as complexidades do mundo urbano, mediante a necessidade de proteger o ambiente natural e humano. Por sua vez, os estudos de Hebe Mattos (2006) sobre memória, políticas de reparação e patrimônio cultural entre comunidades quilombolas também indica esse olhar polivante sobre os quilombos, uma vez que os três aspectos abordados por ela se articulam para exigir que se perceba as tensões políticas internas e as demandas articuladas por ações políticas afirmativas para os territórios em diferentes setores, não somente o aspecto fundiário e territorial. Quando olhamos especialmente o contexto da região Oeste do Pará, a pesquisas de Assumpção Amaral (2008) e de Eurípedes Funes (2009) sobre a formação sócio-histórica heterogênea das comunidades quilombolas desta região, percebemos que a perspectiva interpretativa que apresenta diferentes trajetórias históricas das comunidades tradicionais no Brasil do Norte nos força a destacar essa polivalência, especificamente, olhar para diferentes modalidades de formação do território, que envolve a fuga, mas também a compra, a herança e ocupação espontânea da terra.

Hebe Mattos assinala também que ao serem reconhecidos como sujeitos políticos coletivos, indivíduos de comunidades quilombolas podem ser vistos dentro de um longo processo histórico de metamorfose social que envolve associações tensas entre identidade negra e memória do cativeiro, reminiscência familiar e tradição cultural, estigmas raciais e expressões festivas e folclóricas (MATTOS, 2006, p. 16). Para Assumpção Amaral, os grupos "redefinidos como comunidades remanescentes de quilombo" incluem nos seus processos de organização como coletividade a reivindicação por uma identificação étnico-racial a partir da cidadania e da autoconsciência de possuir um território e uma prática de gestão participativa, bem como a forte preocupação com a Floresta Amazônica como expressão de uma forma de sobrevivência através dos recursos naturais, animais, vegetais e minerais. Estes elementos são fundamentais aos comunitários e expressam uma forma particular de lidar com as questões da terra e do meio ambiente (AMARAL, 2008, 188). Na luta pela própria existência os grupos quilombolas da região oeste do Estado do Pará inventaram e reinventaram múltiplas formas de lidar com as condições sociais existentes, resultando em respostas heterogêneas a tais condições, ao mesmo tempo em que as próprias 
concepções sobre as maneiras de lidar com o contexto sócio-ambiental também resultaram em caminhos distintos. Uma vez que a posse comunitária, o tipo de utilização e a finalidade do território distanciam as comunidades quilombolas dos posseiros, “(...) aos quilombolas como indivíduos cabe o direito de explorá-las segundo as normas e os costumes do grupo", mantendo um certo equilíbrio entre a posse coletiva e democrática da terra e uso individual como um esteio valorativo do grupo" (AMARAL, 2008, p. 189).

Se a partir desta abordagem materialista o reconhecimento legal do território historicamente ocupado aparece como o aspecto reivindicatório central entre comunidades quilombolas da região Oeste do Pará, devemos conceber esta demanda como um elemento também diretamente ligado à valorização de práticas culturais que compreendem elementos cosmológicos, míticos, "folclóricos" e conhecimentos tradicionais, portanto sob a abordagem culturalista. Estes conhecimentos tradicionais se expressam de formas plurais e devem ser registrados em cartografias sociais que são “(...) refeitas em conformidade com o tempo histórico em que os territórios estão situados" $"$.

É neste ponto que se insere a discussão sobre a existência de uma “institucionalização" destes aspectos sócio-culturais e históricos em debates sobre a escolarização nestes territórios quilombolas - provavelmente o direito público minimamente presente na maior parte destes territórios. Ocorre que o lugar do debate sobre educação escolar quilombola (e seus aspectos pedagógicos, conceituais e profissionais), tem lugar, no máximo, lateral nas discussões sobre regulamentação fundiária e sobre demandas econômicas. Assim, a educação nos territórios quilombolas como um elemento estratégico na construção de táticas políticas para obtenção da regulamentação fundiária, isto é, reconhecimento e titulação dos territórios quilombolas como passo fundamental para acesso à serviços básicos de saúde, educação e transporte.

Em termos legais, a educação escolar quilombola, conforme o estabelecido pelas orientações presentes nas Diretrizes Curriculares Nacionais para a Educação Escolar Quilombola na Educação Básica ${ }^{4}$ instituída em 2012, deve(ria) ter como referências teórico-práticas um conjunto de saberes tradicionais que compreendem tais experiências

\footnotetext{
${ }^{3}$ Resolução n.8, 20/11/2012, CNE/CEB 8/2012. DOU, Brasília, 21/12/2012, Seção 1, p. 25.

${ }^{4}$ Resolução n.8, 20/11/2012, CNE/CEB 8/2012. DOU, Brasília, 21/12/2012, Seção 1, p. 26.
} 
históricas registradas e, também, aquelas narradas pelos sujeitos das comunidades, bem como a valorização de suas práticas econômicas, religiosas e coletivas no locais de origem.

$\mathrm{Na}$ educação escolar quilombola, tais saberes deve(riam) se tornar parte do espaço sócio-educativo que efetive o diálogo entre o conhecimento escolar e a realidade local, valorizando o desenvolvimento sustentável, o trabalho coletivo e individual e a luta pelo direito à terra e ao território e à diferença cultural. Vale registrar que a lei 10.639/2003 oficializou o registro da temática "identidade quilombola" como parte dos conteúdos a serem abordados na educação básica. Esta leia partiu de um debate público que criticou diretamente uma historiografia oficial que durante anos permitiu que se representasse a história das populações negras, suas culturas e práticas religiosas como inferiores ou relegadas à um status epistemológico de segunda categoria. Esta lei também explicitou uma realidade gritante na sociedade brasileira: a presença e a participação política ativa de negros nas lutas contra o preconceito racial no espaço urbano e no mundo rural.

As diretrizes da educação escolar quilombola estabelecem que o ensino ministrado nas escolas quilombolas deve ser informado pela memória coletiva da comunidade, pelas especificidades linguísticas remanescentes, pelos marcos civilizatórios e práticas culturais, pelas tecnologias e formas de produção do trabalho, pelos acervos e repertórios orais, festejos, usos do espaço e tradições culturais, pelos demais elementos que conformam o patrimônio cultural das comunidades quilombolas de todo o país e, em especial, pela territorialidade como referencialidade identitária. Pensar a educação escolar quilombola, é, portanto, mobilizar para dentro dos espaços escolares os processos sócio-culturais de uso do território, compor territórios curriculares que não tornem a escola quilombola somente pautada em uma referência geográfica.

\section{PROFESSORAS NO QUILOMBO, PROFESSORAS DO QUILOMBO: POLÍTICA E PEDAGOGIA}

Se a educação escolar quilombola tem sido concebida a partir da articulação de diferentes processos de construção de etnicidades e memórias históricas presentes nas 
narrativas dos sujeitos pertencentes ao mundo comunitário, faz-se necessário construir debates sobre a implementação desta modalidade de ensino também a partir do que os professores destas escolas estão fazendo e como estão fazendo suas pedagogias, tomando como ponto de partida elementos referentes às realidades sociais e práticas culturais, políticas e materiais das diferentes comunidades quilombolas, com suas peculiaridades e especificidades (NUNES, 2016, 166).

Algumas discussões conceituais sobre uma pedagogia escolar quilombola tem considerado as narrativas dos sujeitos das comunidades como referencialidades necessárias para elaborar conteúdos para uma educação quilombola (DA SILVA, 2013). Estas discussões tem chamado atenção tanto para um “(...) espaço escolar que reflete a sociedade e suas contradições, sendo palco de conflitos e desigualdades múltiplas e sobrepostas" (CARRIL, 2017, 551), o que envolve proposições de um currículo aberto, flexível e interdisciplinar. Neste debate, há argumentos à favor da mobilização de "aspectos globais do sistema de ensino, aspectos gerais das próprias comunidades quilombolas e especificidades de cada uma, ou pelo menos de cada região" (SILVA, 2011 , 14) na composição deste currículo, que deve partir dos próprios sujeitos da escola. Um estudo sobre esta modalidade de ensino, portanto, pode partir das narrativas e posicionamentos políticos feitos por aquelas e aqueles que atuam na escolarização dentro das comunidades. As/os próprias professoras/es e gestoras são o ponto de partida para discussões crescentes sobre as contradições do trabalho docente e sobre o lugar social destinado a esta docência no cotidiano dos territórios quilombolas.

Viver nos quilombos equivalia a arar e cultivar a terra para dela extrair os recursos necessários à vida e também dela fazer sua moradia e nela reconstruir seu suporte cultural, em uma perspectiva de sobrevivência. É nesse sentido que a vida cotidiana que se vê ameaçada pode ser o ponto de partida para um projeto de educação quilombola que revele e supere as representações e práticas que separam os sujeitos de suas culturas, racionalizando os usos do espaço (CARRIL, 2017, 556)

Estas orientações, entretanto, devem ser confrontadas com análises sobre como as práticas de educação nas comunidades quilombolas decorrem de um currículo escolar quilombola que reconheça a identidade e a cultura quilombola tal como ela se apresenta concretamente, percebendo quais elementos podem e devem ser transformados em conteúdos escolares a partir de um mínimo de concordância e diálogo com essas comunidades. É necessário perceber como estão organizadas as escolas que atendem 
crianças, jovens e adultos residentes nestes territórios quilombolas, observando o cotidiano destas comunidades, bem como as próprias práticas pedagógicas dos professores e administradores deste estabelecimentos de ensino. Por isso, criar um espaço de discussão dentro da universidade no qual professores, pesquisadores e administração do ensino público local possam trocar e analisar experiências de ensino em funcionamento, discutir conceitos e práticas pedagógicas e propor ações para o aperfeiçoamento do ensino e das condições de ensino nas escolas dentro dos territórios quilombolas é parte fundamental deste processo de construção de uma identificação de como esta educação escolar quilombola é realizada cotidianamente.

As práticas pedagógicas das/os professoras/professores de uma escola quilombola na cidade de Santarém, que oferece turmas de primeira à nona série do ensino fundamental, cuja missão educacional é descrita no projeto político pedagógico como uma: "busca de uma educação racial igualitária, respeitando e fortalecendo as raízes negras em suas diversidades culturais", serão apresentadas para o objeto de análise deste artigo. A partir de registros etnográficos, discussões grupais e relatos individuais obtidos em três (3) oficinas temáticas realizadas com as professoras da Escola de Ensino Fundamental São Pedro ${ }^{5}$, localizada na Comunidade quilombola do Bom Jardim, na cidade de Santarém, traremos apontamentos, discussões e ideias elaboradas pelas professoras sobre três aspectos ligados ao que se denomina por pedagogia escolar quilombola, isto é, I) como refletem sobre suas próprias práticas pedagógicas dentro da escola, II) o que pensam sobre o processo de escolarização realizado em uma escola concebida ora como "escola quilombola", ora como "escola no quilombo" e III) como definem conceitualmente Educação Escolar Quilombola.

Dentre as sete (7) professoras participantes das oficinas, apenas duas (2) são nascidas e residentes na comunidade ${ }^{6}$. Esta origem, logo na primeira oficina temática,

\footnotetext{
${ }^{5}$ As oficinas temáticas foram realizadas, respectivamente, nos meses de outubro de 2018, maio e agosto de 2019 e o conteúdo das discussões foi registrado com o consentimento das participantes. Estivemos na escola pelo menos uma vez por mês, nos anos de 2017, 2018 e 2019, em todos os meses letivos, isto é, março até junho e agosto até dezembro.

${ }^{6}$ Identificarei as 7 professoras como professoras quilombolas A e B e professoras não-quilombolas C, D, E, F e G. Todos os profissionais que participaram das oficinas temáticas nas séries do ensino fundamental e em turmas de ensino infantil. As duas professoras quilombolas são graduadas em Pedagogia e duas professores não-quilombolas C e D em História e Geografia, todas pela Universidade Federal do Oeste do Pará (UFOPA), no sistema modular de ensino do Plano Nacional de Formação de professores da Educação Básica (PARFOR). As outras três professoras E, F e G não-quilombolas são graduadas em faculdades particulares, em Pedagogia, Matemática e Letras.
} 
apareceu indiretamente nos relatos da maior parte das professoras. Se para todos os professores o processo de aprendizagem ocorre na escola e na "vida do dia-a-dia da comunidade", são os dois professores negros quilombolas que farão a defesa pela mudança de horário que permite o acesso às aulas pelos alunos que trabalham com suas famílias em certos períodos do ano. O relato abaixo, trazido pela professora quilombola $\mathrm{B}$, é consequência dessa adaptação da instituição à uma realidade que é vista pelos docentes como "em constante mudança". São estas duas professoras quilombolas que, constantemente, são apontadas pelas colegas como as docentes que fazem a escola ser "autêntica", tidas como as que "melhor compreendem" a dinâmica social da comunidade. $\mathrm{O}$ trecho de relato abaixo aponta para esta melhor compreensão da realidade vivida na comunida e, especialmente, experienciada no trabalho docente realizado dentro da instituição:

Quando chega no período no cultivo do açaí, de colheita de frutas da época, da colheita de legumes que plantam aqui [na comunidade], que inclusive enviam para merenda aqui [na escola], muitos alunos precisam ajudar suas famílias, o que faz com que eles não venham pra escola entendeu? E antes, até a escola dava falta para essas crianças, mas depois percebemos que a escola aqui [na comunidade] precisa se adaptar a essa situação né? Que é uma realidade daqui que os alunos não podem receber falta por estarem no trabalho com a família, e aí eles, a gente... Permite que eles venham no outro turno, para assistir aula, no turno da tarde e fazer atividades em casa (Professora quilombola A)

Para as professoras não-quilombolas, a "valorização e respeito da identidade negra e quilombola" (Professora não-quilombola C), o "ensinar a família a fazer com que o aluno respeite e aceite sua própria identidade de quilombola" (Professora nãoquilombola E) e o "resgate dos antepassados para a compreensão da cultura negra" (Professora não-quilombola D) são os principais desafios político-pedagógicos para a construção da docência em uma escola quilombola na comunidade. Para os professores quilombolas, por sua vez, são questões administrativas que envolvem a não consulta às comunidades sobre o ingresso de professores não-quilombolas, a inexistência de uma política de formação contínua de professores, a pouca merenda escolar enviada pela prefeitura e a inexistência de uma estrutura predial adequada para a realidade dos estudantes quilombolas que frequentam a escola que aparecem como os principais desafios político-pedagógicos que precisam ser enfrentados pela instituição. 
Para todas as professoras, a escola é uma "instituição aberta a comunidade", "aberta as lideranças da comunidade" e é flexível às demandas trazidas pelos familiares dos alunos. Esta participação da comunidade na escola ocorre em vários aspectos da vida escolar, isto é, nos debates sobre temas escolares, como ensino de literatura, ensino de ciências, ensino de educação física, organização da semana da pátria, da feira de ciências e até mesmo do planejamento docente. Todavia, ressaltam que sempre há um tema recorrente: o da regularização fundiária das comunidades quilombolas. Todas as professoras consideram que o tema é fundamental para os quilombos da região. Entretanto, assinalam que em espaços de discussão (como reuniões com responsáveis de alunos, representantes do governo municipal e de outros órgãos públicos) nas quais o debate deveria focar em discussões sobre contratação de professores para a escolar, ampliação predial, materiais didáticos, reajuste salarial, etc., algumas discussões dentro da comunidade retomam, diretamente ou indiretamente, questões sobre regularização fundiária de outras comunidades em detrimento das demandas específicas da escola.

Para os professores quilombolas, para tentar tencionar o ensino de um conteúdo do currículo oficial que ainda obedece hegemonicamente uma norma e uma lógica epistemológica dominante (NUNES, 2016, 169), a escola precisa ensinar a própria história da comunidade. Para a professora B, este ensino é trazido para a escola nos materiais didáticos produzidos pelas/os professoras, pela participação das lideranças, pelos sábios, benzedeiros e curandeiros da comunidade e da região. Porém, é necessário produzir pesquisas nas universidades que tragam outras bases de saberes e de conhecimentos que possam se transformar em outros conteúdos. Para a professora quilombola B, “a cultura da comunidade é a lembrança, é uma memória que alguns velhos têm na comunidade, entende? Imagina que se essas pessoas morrem? Tem um pedaço de história que perde" [sic]. Assim, autonomia curricular, autogestão pedagógica e participação política em conselhos educacionais locais e em outras instâncias decisórias são apresentados como elementos necessários para a existência de uma escola cidadã quilombola, na qual a criança é o ator fundamental, sujeito imprescindível que precisa ser considerado no projeto político-pedagógico feito a partir de saberes populares, base do conhecimento escolar (GALVÃO, 2016, 197). Esses elementos apareceram nos relatos da professora quilombola A. 
Quando os professores não-quilombolas responderam à pergunta: quais são os temas mais importantes para discutir em sala de aula em uma escola quilombola? Palavras-chave como "diversidade", "valorização da identidade negra dos alunos como quilombolas", "respeito aos mais velhos", "solidariedade", "igualdade" e "amor" foram as que apareceram nas respostas. Para a professora não-quilombola $\mathrm{D}$, a escola deve ter como "foco" a discussão social:

\begin{abstract}
"O amor próprio entre os alunos, as crianças, os adolescentes né? A questão de saber as própria cultura, de saber as próprias origens, a questão da autovalorização como negro, a origem negra tem que ter um acolhimento na escola, tem que ter um acompanhamento pedagógico do professor junto com a família, tem que ter um trabalho com a memória, as fontes, para que a criança entenda as própria história dela" (Professora não-quilombola D)
\end{abstract}

Para as professoras não-quilombolas $\mathrm{F}$ e $\mathrm{G}$, é a prática escolar cotidiana que faz com que o profissional apreenda a cultura local. Para estas professoras, aquele autocuidado entre os alunos decorreria da valorização o respeito recíproco, da valorização desta cultural local, o que pode evitar a ocorrência de constantes práticas ofensivas, como apelidos e xingamentos raciais, entre os próprios estudantes negros e quilombolas da escola. Para estas duas professoras, o ensino do que nomeiam como "cultura local" (incluindo ensinamentos sobre identidade racial, história da ocupação do território, práticas religiosas, etc) é visto como um “caminho pedagógico" para se opor à estas práticas de ofensa racial entre os estudantes. Para a professora não-quilombola $\mathrm{G}$, existe uma ideia de "superioridade cultural" atribuída às pessoas do espaço urbano (no qual seriam vistas como mais inteligentes porque teriam acesso à tecnologia) presente em falas de alguns alunos da escola que precisa ser modificada.

Para esta mesma professora não-quilombola $\mathrm{G}$, esta mudança na auto-estima dos estudantes decorre diretamente da ação de positivação de identidades, de valorização da cultura quilombola e da identidade negra durante o trabalho pedagógico na escola. Vistas como categorias sinonímicas pela professora não-quilombola $\mathrm{G}$, a "cultura quilombola" e a "identidade negra" podem ser, por assim dizer, ensinadas na escola, pois a escola é um lugar para também ensinar "cultura".

ESCOLARIZAR COM CULTURA, ESCOLARIZAR A CULTURA 
Para a professora não-quilombola G, recém-chegada à escola em 2018, ano em que realizamos a primeira oficina temática, suas reflexões sobre a relação entre cultura e escola a partir do contexto de relações existentes na comunidade apontam para uma cultura de solidariedade forte entre os comunitários em eventos festivos e de lazer, em atividades de mutirão agrícolas (colheitas e pescas) e em discussões políticas sobre regularização fundiária e uma solidariedade fraca para ações que envolvam a educação.

Para ela, a pouca relação entre escola e comunidade decorre desta "cultura das pessoas", que precisa ser modificada, assim como precisa ser modificada a esta "superioridade" atribuída às pessoas da cidade pelos próprios estudantes da escola. Para a professora não-quilombola $\mathrm{G}$, se por um lado os estudantes adolescentes e algumas crianças da escola são ensinados a respeitar as tradições religiosas, mitos e alguns rituais existentes na comunidade, por outro lado, a "identidade dos meninos e das meninas não é assumida, entende? É por isso que tem que ser trabalhado isso na escola" [sic]. Ela faz menção positiva à um certo cooperativismo informal que existe na comunidade, sobretudo no que diz respeito aos mutirões de roçado, limpeza de terrenos, reformas e construções de residências e eventos festivos. Para a professora não-quilombola $\mathrm{E}$, em certas situações estes trabalhos coletivos afastam os estudantes da escola por certos dias ou períodos do mês, o que, em alguns casos, traz dificuldades para o cumprimento das atividades curriculares, resultando em dificuldades de aprendizagem e em reprovações.

Neste aspecto, a professora não-quilombola $\mathrm{E}$ parece se posicionar de modo distinto da professora quilombola A. Esta, por sua vez, parece se posicionar a favor de uma adaptação da cronologia escolar, dos métodos de avaliação e das metodologias de ensino às crianças e adolescentes que precisam se ausentar da instituição em certos períodos do ano letivo para ajudar familiares, parentes e outros comunitários em colheitas, plantios, pescas e trabalhos coletivos dentro do território quilombola. Embora a escola ofereça essa flexibilidade curricular aos estudantes que precisam se ausentar dela em função de demandas extraescolares, talvez o relato da professora nãoquilombola $\mathrm{E}$ indique que o cumprimento desta orientação de flexibilização não é seguida efetivamente por todas os profissionais da escola.

Vale destacar que é a professora não-quilombola $\mathrm{C}$ quem fez observações acerca do que considera como elementos específicos existentes nesta cultura quilombola. A professora não-quilombola $\mathrm{C}$, em seu registro escrito, desenhou um quadro que 
responderia à pergunta: o que tem na escola quilombola e o que não tem? No quadro abaixo, ela enumera alguns elementos relativos à comportamentos sociais coletivos e individuais, valores morais e pedagógicos que seriam aspectos importantes para a definição de uma escola quilombola:

Quadro A: "o que define educação quilombola e o que não define educação quilombola"

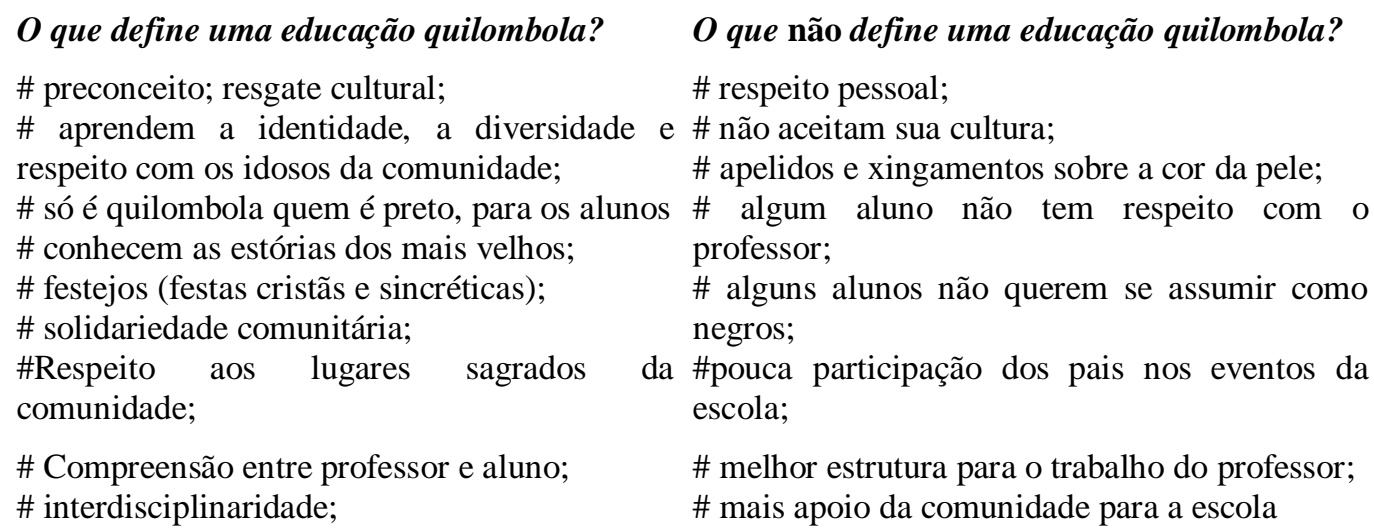
Fonte: pesquisa de campo, março-junho/agosto-dezembro, 2017/2018/2019

As observações que a professora não-quilombola $\mathrm{C}$ realiza decorre, por um lado, de uma natureza "comunitária" da escola no que se refere à circulação dos estudantes nos espaços da instituição. É comum ver crianças e adolescentes visitando o estabelecimento em horários distintos dos horários letivos, conversando com as funcionárias da escola, brincando com outros alunos ou circulando na área usada como espaço de lazer. Por outro lado, as mesmas observações também nos permitem apontar para uma concepção ambivalente da professora sobre educação quilombola. Ou seja, embora os estudantes "conhecem a história dos mais velhos", "respeitam os lugares sagrados" e "compreendem o professor", não se oferece, todavia, "apoio ao trabalho dos professores", não há "participação da comunidade nos eventos escolares" e não se verifica o que se define como "aceitação da própria cultura" por parte dos estudantes. A ambivalência, ao que parece, é um termo adequado para apontar a maneira pela qual a professora não-quilombola $\mathrm{C}$ concebe algumas contradições e desafios que enfrenta, ao lado dos colegas de trabalho, na escola e na comunidade. 
Os professores da escola declararam, fora das discussões internas nas oficinas temáticas, que, se por um lado a "educação quilombola" tem uma lei que ampara e obriga sua aplicação no currículo escolar, por outro lado é realizada de maneira prática por poucos professores. Especificamente, parece que os professores sugerem existir um conjunto de atividades escolares, práticas de construção de conteúdos sobre a realidade local e iniciativas ocasionais para confecção de materiais didáticos que prescinde de uma certa pedagogia, que está pouco amparada em um corpus articulado de diretrizes teóricas que orientem conceitualmente o trabalho prático.

Entre os professores quilombolas, registrei comentários que apontaram para uma visão anacrônica existente entre professores da rede de ensino. Em alguns fóruns e espaços de formação docente, sobretudo em reuniões realizadas em períodos de planejamento escolar nas primeiras semanas do ano letivo, muitos destes professores revelaram total desconhecimento da lei 10.639. Também indicaram a existência de ideias e concepções ultrapassadas sobre comunidades quilombolas e comunidades negras rurais que revelam uma visão distorcida e estigmatizante ainda atrelada ao século XVIII e XIX, como se fossem comunidades isoladas e atrasadas materialmente.

Embora todos os professores da escola concordem que em uma escola quilombola a educação tradicional que se preocupa somente com o conhecimento formal e ocidental deva dar espaço para as variadas manifestações culturais existentes nos quilombos, sua história local e eventos cotidianos, esta mesma escola quilombola deve deve incluir no currículo formal temas, debates e conteúdo que localizem as comunidade quilombolas nos processos históricos do racismo, que explicite como o preconceito racial é parte da formação cultural destas comunidades. Para explicar aos estudantes porque são tratados de maneira diferente quando estão no espaço urbano da região metropolitana de Santarém, os professores parecem sugerir que a escola precisa falar sobre como se construiu, no Brasil, uma ideia persistente de inferioridade racial. Ao fazer essa conexão narrativa outros professores da rede pública de ensino poderiam entender as razões pelas quais "o negro foi tido como uma raça inferior, na qual não tinha nem alma e muito menos educação" (professora quilombola A). A professora quilombola B, por sua vez, estende suas considerações críticas para todo o sistema de ensino nacional: 
A educação como um todo, se tu for observar, sempre foi pensada para o branco e não para o negro. Nesse sentido, é comum que os professores, quando chegam na comunidade [quilombola], terem esse pré-julgamento de discriminação entre negros como se fosse coisa criada pelo negro, devido as informações distorcidas e a cultura negativa criada pelo sistema de ensino brasileiro. Como alguns professores não tem uma visão mais aberta ou mais crítica, conseguem ver apenas isso, não percebem que o sistema foi pensado justamente para que isso aconteça. Quem quer ser negro se negro é inferior? (Professora quilombola B)

Em algumas conversas informais com professores e gestores da escola, surgiram comentários sobre os esforços cotidianos dos professores não-quilombolas alocados em escolas quilombolas /escolas nos quilombos para realizar um trabalho simultâneo de desnaturalização de ideias, valores e visões de mundo apreendidas no mundo urbano e de familiarização com o "mundo dos quilombolas", o que demandaria um trabalho de aprendizagem, pesquisa e compreensão da história contada pelos integrantes da comunidade, da compreensão das vivências culturais e do desenvolvimento de diferentes estratégias para conceber o processo de aprendizagem como “(...) um exercício 'incentivador', levando os educandos a usar seu conhecimento no enfrentamento dos desafios propostos na sociedade. Eles contribuirão de fato para a implementação de uma política educacional voltada para tal população quilombola" (Professora não-quilombola E)

Uma vez que o reconhecimento de que a sociedade brasileira e, especificamente, a sociedade local é "como o todo muito preconceituosa e coloca nos meios de comunicações uma única identidade que a gente aprende, foi preciso eu trabalhar aqui para perceber melhor isso" (Professora quilombola C). Um dos temas da semana de planejamento da escola em 2018 envolveu uma discussão sobre juventude e identidade negra. Conversando sobre os resultados desta discussão no trabalho em sala de aula, tanto a professora quilombola $\mathrm{B}$ como a professora não-quilombola $\mathrm{D}$ afirmaram que passaram a dar atenção para como os adolescentes da comunidade vivenciam um processo de reconhecimento identitário de integrantes da comunidade "mais com base na cor da pessoa", o que, para elas, não ocorre com os processos de identificação realizados pelos pais e avós. Para as professoras, os jovens da comunidade, com acesso à discursos sobre racialização "explícitos", existentes nas mídias sociais e em outros espaços de debates políticos, na participação em movimentos sociais locais e em eventos artísticos e culturais no espaço urbano, tendem a conceber 
que a racialização "com base na cor da pessoa" é o que mais importa para definir quem é negro, o que, por sua vez, é o critério fundamental para atribuir quem é quilombola.

“(...) O que eu vejo aqui é que apenas pessoas de pele negras são quilombolas, não levam, eles não levam mesmo em consideração o processo histórico de branqueamento da sociedade como estratégia de ter uma única raça na qual seria a raça branca, então tem pessoas que não tem pele negra que não são quilombolas para eles, mas são pra pais e avôs deles entende?" (Professora não-quilombola D)

Era comum, sobretudo ao final do dia letivo, quando conversava com professores e direção da escola, relatos que classificavam a atuação docente na escola como um "grande desafio cotidiano", destacando como um argumento o número insuficiente de professores quilombolas com formação superior para atuar em seus quilombos de origem ou em comunidades próximas. Outro ponto de tensão era a exigência de formação contínua para as professoras e professores quilombolas. Pedidos espontâneos por oferecimento de cursos de atualização em suas respectivas áreas de atuação, solicitações de apoios para tentarem ingressar em cursos de pós-graduação e, através deles, produzirem pesquisas sobre suas comunidades também eram citados diante da minha presença, em conversas informais e antes e depois da realização das oficinas temáticas. Também solicitavam que a gestão escolar da instituição fosse realizada pelos próprios sujeitos das comunidades quilombolas, talvez uma gestão compartilhada entre lideranças, professores quilombolas e secretaria de educação.

Um tema sobre o qual alguns professores citavam era o da "autoestima do negro" entre os "educandos". Se voltarmos ao quadro desenhado pela professora nãoquilombola $\mathrm{C}$ (e outros professores), veremos que um dos elementos que ela registra como um ponto de tensão na escola, entre os estudantes, é, literalmente, que "alguns alunos não querem se assumir como negros". Vimos que o tema da identidade, mais especificamente, o da "valorização da identidade negra e quilombola", reaparece como um problema individual ("alguns alunos"), como um tema de debate político (a participação em movimentos políticos no espaço urbano) e como um aspecto sócio psicológico (autoestima) em diferentes relatos entre as docentes da escola. Expressões como "valorização de sua representação social enquanto quilombola", "comprometimento dos estudantes com a sua historicidade" e "fortalecimento da 
identidade do ser quilombola" eram recorrentes nas discussões realizadas nas oficinas temáticas e em conversas informais.

Aquela polivalência política do termo "quilombo" em pesquisas e estudos acadêmicos clássicos e contemporâneos parecem fazer eco e ter um lugar útil na polissemia presente nas maneiras pelas quais professores concebem suas práticas docentes e, ao mesmo tempo (talvez espontaneamente), uma pedagogia escolar quilombola. Há uma notável diferença nas maneiras pelas quais se exprime este trabalho docente entre professoras quilombolas e professoras não-quilombolas e, sobretudo, nas maneiras pelas quais elas se posicionam diante da condução administrativa, financeira e pedagógica da educação quilombola na escola.

\section{CONSIDERAÇÕES FINAIS}

A partir de uma síntese de pesquisas sobre história da ocupação territorial, dinâmicas políticas da formação cultural e processos de territorialização entre comunidades quilombolas, indicamos que alguns desdobramentos práticos a partir destes elementos estão presentes nas reflexões sobre as próprias práticas pedagógicas dentro da escola, realizadas pelas professoras que atuam no Oeste do Pará, na Amazônia brasileira. Estes desdobramentos influenciam modalidades discursivas sobre como ocorre o processo de escolarização, concebido de maneira variável a partir de uma "escola quilombola" e, ao mesmo tempo, de uma "escola no quilombo". Tais desdobramentos delineiam narrativas e relatos individuais usados para definir pedagogicamente o que cada docente concebe como "quilombo" em sua prática profissional.

Destacamos três pontos de consonância ou dissonância entre dois grupos de relatos para indicar diferentes posicionamentos pedagógicos das professoras quilombolas em comparação com as professoras não-quilombolas. Três dimensões foram indicadas para mediar estes distintos posicionamentos. A primera se refere às maneiras pelas quais a experiência comunitária é trazida para a prática docente, medindo nas conversas formais e informais entre os agentes da escola quem tem mais ou menos conhecimento sobre a cultura do quilombo, "quem mais conhece" ou "quem menos conhece" a realidade do quilombo e "quem mais consegue" ou "quem menos 
consegue" regular o que é pedagogicamente importante para a prática escolar no quilombo. A segunda se define pelas concepções que as professoras sugerem ser as mais adequadas sobre uma certa pedagogia escolar quilombola que, embora necessite ser melhor elaborada conceitualmente, envolve valores e finalidades distintos quando se consideram as ideias e opiniões pessoais entre os dois microgrupos de professoras. Já a terceira dimensão envolve os diferentes lugares ocupados pelas discussões sobre racismo, identidade étnico-racial e auto-estima nas práticas docentes das professoras. Emboras sejam tidos como fundamentais para o debate na escola, a relevância de cada um dos três "temas" parecem ter pesos diferentes quando se considera o quê e como as crianças e adolescentes na escola devem ser ensinados, atribuindo, por assim dizer, ordens de relevância pedagógica e política de certo modo opostas aos debates sobre racismo, identidade étnico-racial e auto-estima. O que se destaca, por fim, é a necessidade de prever a existência de posicionamentos políticos heterogêneos entre os docentes dentro de qualquer escola, incluindo a escola em comunidades quilombolas.

\section{REFERÊNCIAS BIBLIOGRÁFICAS}

ALMEIDA, Alfredo Wagner. Terras de Preto no Maranhão: Quebrando o Mito do Isolamento. São Luís: Centro de Cultura Negra do Maranhão, (CCN-MA) e Sociedade Maranhense de Direitos Humanos, 2002.

- Territórios e Territorialidades específicas na Amazônia: entre a "proteção" e o "protecionismo". Caderno CRH, Salvador, v. 25, n. 64, p. 63-71, jan./abr, 2012.

AMARAL, Assunção J. P. Remanescentes das Comunidades dos Quilombos no interior da Amazônia - conflitos, formas de organização e políticas de direito à diferença. Cadernos do CEOM, Ano 22, n. 30, 2008.

CARRIL, Lourdes. Os desafios da educação quilombola no Brasil: o território como contexto e texto. Revista Brasileira de Educação, v. 22, n. 69, abr-jun, 2017.

DA SILVA, Paulo Sérgio. Contornos Pedagógicos de uma Educação Escolar Quilombola. Paulo Sérgio da Silva, 2013. TESE (Doutorado) Universidade Federal do Rio Grande do Sul, Faculdade, 2013

FREIRE, Jonis; AMANTINO, Márcia. Ser homem, Ser escravo. In: DEL PRIORE, Mary; AMANTINO, Marcia. (orgs.) História dos homens no Brasil. Editora UNESP, 2013, pp. 15-48

FUNES, Eurípedes. "Nasci nas matas nunca tive senhor": história e memória dos mocambos do Baixo Amazonas (Tese de doutorado), Universidade de São Paulo, 1995.

Mocambos: natureza, cultura e memória. Revista História, Unisinos 13(2): p. 146153, Maio/Agosto, 2009. 
GALVÃO, Mariana. Por uma Escola Cidadã Quilombola In: SOUZA, Edileuza; NUNES, Georgina; MELO, Willivane. Memória, Territorialidade e Experiências de Educação escolar quilombola. Editora UFPeL, 2016, p. 197-222

GOMES, Flávio. Mocambos e Quilombos: uma história do campesinato negro no Brasil. São Paulo: Companhia das Letras, 2015, p. 70-72

MOURA, Clóvis. Quilombos: resistência ao escravismo. São Paulo, Editora Ática, 1993

MATTOS, Hebe. "Remanescentes das Comunidades de Quilombos": memórias do cativeiro e políticas de reparação no Brasil. Revista USP, n. 68, p. 104-111, (Dez-Fev), 2006

NUNES, Georgina. Cartografias do sul do país e pedagogias para uma educação escolar quilombola. In: SOUZA, Edileuza; NUNES, Georgina; MELO, Willivane. Memória, Territorialidade e Experiências de Educação escolar quilombola. Editora UFPeL, 2016, pp 159-177.

SILVA, Givânia. Currículo Escolar: identidade e Educação Quilombola. Cadernos ANPAE , v. 11, p. 1-14, 2011.

Recebido em: 30/11/2020

Aprovado em: 25/07/2021 